\title{
Xây dựng một xã hội hài hòa - mục đích của việc bảo vệ chế độ nhà nước hay bảo vệ quyền con người
}

\author{
Nguyễn Đăng Dung ${ }^{*}$, Nguyễn Đăng Duy \\ Khoa Luật, Đại học Quốc gia Hà Nội, 144 Xuân Thủy, Cầu Giấy, Hà Nội, Việt Nam \\ Nhận ngày 12 tháng 4 năm 2017 \\ Chỉnh sửa ngày 25 tháng 5 năm 2017; Chấp nhận đăng ngày 25 tháng 6 năm 2017
}

\begin{abstract}
Tóm tắt: Ở phương Đông đề cập đến việc xây dựng một xã hội hài hòa với mục đích nhằm bảo vệ chế độ nói chung thể hiện qua các đức tính của người quân tử, ở phương Tây việc xây dựng một xã hội hài hòa được biểu cụ thể hơn là các quyền của con người và cơ cấu tổ chức nhà nước .
\end{abstract}

Tù khóa: Xã hội hài hòa, đạo của người quân tử, nhân quyền, phân quyền.

Vấn đề xây dựng một xã hội hài hòa trở thành vấn đề thời thượng được bàn rất sôi nổi cách đây khoảng gần 20 năm ở Trung quốc, kể từ khi Đại hội Đảng Cộng sản Trung quốc lần thứ XVI (2004) rồi dần dần chuyển sang Việt Nam. Nghiên cứu các tư tưởng cùng thực tiễn xây dựng một xã hội hài hòa nhiều, người cho rằng, đó là tư tưởng chỉ có ở phương Đông. Tuy nhiên, không hoàn toàn như vậy, vấn đề đó không chỉ có trong xã hội của các nhà nước phương Đông, mà còn có cả ngay trong nhà nước của phương Tây. Bên cạnh những điểm chung, giữa phương Đông và phương Tây cũng tồn tại những điểm khác biệt nhất định.

\section{Xây dựng xã hội hài hòa của phương Đông và mục tiêu bảo vệ chế độ nhà nước}

Động lực chính yếu cho việc duy trì trật tự xã hội ở phương Đông không phải pháp luật mà là đạo đức - sự rèn luyện nhân phẩm mà sau

\footnotetext{
*Tác giả liên hệ. ĐT.: 84-24.37549713

Email: dangdung52.pld@gmail.com

https://doi.org/10.25073/2588-1167/vnuls.4080
}

này được gọi là nhân trị gắn liền với các học thuyết Nho giáo, Đạo giáo và có phần Phật Giáo. Khái niệm hài hoà là đặc điểm của văn hoá Trung Quốc truyền thống, chữ "hoà" xuất hiện cách đây 3000 năm ở đời Tây $\mathrm{Chu,} \mathrm{Khổng} \mathrm{tử} \mathrm{và}$ Lão Tử đề cao sự hài hoà với tự nhiên. Lão Tử cho rằng, lịch sử phát triển ngày càng mau, xã hội ngày càng phân hoá, con người trong xã hội ngày càng bị xé nát, cá nhân xung đột với xã hội, sinh ra hỗn loạn không thể cứu vãn được, do đó phải trở về với tự nhiên là cái nguồn sinh ra nhân loại, ông phê phán sự bóc lột thậm tệ và ăn chơi xa hoa của giai cấp thống trị, ông đòi hỏi bọn thống trị phải tuân theo quy luật tự nhiên. "Đạo" theo Lão Tử, chủ trương để mọi việc tiến triển theo con đường của nó, nghĩa là tự nhiên, dịu dàng, và không ích kỉ, đề cao sự hiền lành, tránh tranh chấp, xung đột [1, tr.258]. Đó là thực chất của hài hoà. Khổng Tử, vào thời Xuân Thu, đã chủ trương giải quyết mọi việc bằng hòa bình và hài hòa. Đó là cơ sở của triết học truyền thống của người Trung quốc. Phát triển các quan điểm của Khổng tử, Mạnh Tử đề xuất một cách đầy đủ hơn. Ông nói, xã hội tốt là người nghèo và già vẫn sống đầy đủ, và phải có một hệ thống chính trị bảo vệ được 
công bằng xã hội [1, tr.176]. Đó là xã hội hài hòa của ông.

Văn hóa Ân độ với mục đích hài hòa và hợp nhất. Đây là ý nghĩa chữ “yoga”. Hầu như tất cả các tôn giáo của phương Đông, nhất là Phật giáo của Bàlamon đều nhấn mạnh chữ Hòa, nghĩa là sự hài hòa của 3 lĩnh vực Thiên, Địa, Nhân. Chính vì lý tưởng chung này mà Phật giáo Đại thừa dễ dàng đi vào vùng Đông Nam Á, đã trở thành cột trụ chính làm cho triết học và văn hóa bản địa phát triển. Bởi vì mục đích của Đại thừa là sự hòa hợp, hợp nhất của sinh tử và Niết bàn, của Sắc và Không, của con người, chúng sinh và Phật tính, của đời và của đạo. Con đường Đại thừa là chuyển hóa mà không loại bỏ, chuyển hóa thế giới thành những quốc gia thanh tịnh và an vui, chuyển hóa con người thành những bậc cao cả mà chúng ta gọi là Bồ tát - Phật.

Đó là lý tưởng chung của nhiều nền văn hóa và tôn giáo, dù giữa họ có những quan niệm khác nhau về cái thực tại. Một xã hội hài hòa và hợp nhất, luôn luôn là lý tưởng soi đường cho sự phát triển của con người. Phật giáo là một trong những tôn giáo với rất nhiều phương pháp luôn luôn nhắm đến sự hiểu biết và tình thương của con người - Trí tuệ và Từ bi, với rất nhiều niềm tin vào chính con người - Tín, rất nhiều hành động vị tha - Hạnh, rất nhiều chí nguyện Nguyện, đã từng giúp cho nhiều xã hội phương Đông tồn tại và phát triển. Đi vào cụ thể xã hội hài hòa của phương Đông tập trung vào những điểm sau:

\section{Hài hòa giũua con người và tụ nhiên}

Tự nhiên có quy luật chung mà con người phải tuân theo. Theo quan niệm của Dịch học, trời có đạo của trời, đất có đạo của đất, con người có đạo của con người: "Để thành đạo trời thì có âm và duơng, để thành đạo đất thì có nhu và cuoong; còn thành đạo người, thì có nhân và nghĩa." Đạo của trời đất ở đây có thể được hiểu là quy tắc, quy luật âm dương, cương nhu của giới tự nhiên, còn đạo người chính là quy phạm đạo đức và nguyên tắc trị quốc (Đạo của người quân tử). Đạo của con người cần và phải thuận theo đạo trời, tức là con người cần phải tuân thủ các quy luật của tự nhiên.

Quan niệm hài hòa giữa trời và người được nhắc đến nhiều lần trong "Kinh Dịch". Muốn đạt đến sự hài hòa giữa trời và người thì vấn đề phải giải quyết đầu tiên là "Nghiên cứu đến cùng sư thần diệu của sư vật để nhận rõ sư biến hóa của sư vật". Trong "Hệ tù thuoong truyện" viết: "Thánh nhân nhờ Dịch mà nhận thức sâu sắc và xét được sự việc tù khi mói manh nha. Nhờ nhận thức sâu sắc nên mới thông hiểu được cái chí của thiên hạ, nhờ xét được sư việc tù khi mói manh nha nên mới hoàn thành được moi việc trong thiên hạ." Nhận thức sâu sắc và xét đoán từ lúc manh nha chính là "Nghiên cứu đến cùng thần diệu của sự vật để nhận rõ sự biến hóa của sụ vật". Quan điểm này đã khẳng định năng lực nhận thức của con người, xác nhận lại khả năng của con người trong quá trình nhận thức tự nhiên, nhận thức bản thân, mở ra hướng lý giải sự ảo diệu của thiên nhiên. Điều này cũng thể hiện một lần nữa không chỉ triết học phương Tây mới chú trọng đến lĩnh vực nhận thức luận, mà triết học Nho giáo, đặc biệt là Dịch học cũng rất chú trọng đến vấn đề này.

Tư tưởng trời người hài hòa trong Nho giáo và Đạo giáo truyền thống một mặt nhấn mạnh đến sự thống nhất và tương tác giữa trời, đất và người, mặt khác lại nhấn mạnh đến tính đặc thù của con người, xác lập quan hệ giữa con người với tự nhiên là một loại quan hệ tích cực và hài hòa chứ không chủ trương chinh phục tự nhiên. Nho và Đạo giáo đều khẳng định sức sáng tạo của đạo trời đầy rẫy trong vũ trụ, và con người "cố gắng theo đức của trời đất, phấn đấu theo sụ sáng suốt của nhật nguyệt, tuân theo trật tụ của bốn mùa", trên cơ sở đó đẩy mạnh, mở rộng tinh thần của đạo "nhân" ra cả xã hội, thậm chí ra toàn bộ giới sinh vật "thảo mộc cầm thú", tạo ra một thể duy nhất bao gồm cả trời đất vạn vật và con người thường gọi là "thiên địa nhân hợp nhất" hay "thiên địa nhân hợp đức", khẳng định giá trị tích cực của quan niệm trời người hài hòa, để từ đó tạo ra một động lực cho quá trình xây dựng xã hội hài hòa. Bởi vì, trên sự gợi mở của triết học của Nho và Đạo, con người và tự nhiên vốn là cùng một gốc, con 
người không được phép làm hại tự nhiên, mà phải tôn trọng tự nhiên, và hơn nữa, là phải thật sự yêu thương tự nhiên, dùng lý trí để khống chế và điều chỉnh hành vi bản thân, khôi phục lại mối quan hệ hài hòa giữa con người và tự nhiên. Trong việc giải quyết mối quan hệ với tự nhiên, con người trải qua ba giai đoạn: sùng bái tự nhiên, chinh phục tự nhiên và hài hòa với tự nhiên. Đặc trưng của mỗi một giai đoạn thể hiện trình độ văn minh của con người trong giai đoạn đó, và cũng chính vì vậy sự phát triển của các giai đoạn chứng minh sự phát triển không ngừng của văn minh nhân loại, sự nhận thức ngày càng toàn diện và sâu sắc hơn đối với giới tự nhiên. Con người có coi tự nhiên là một phần thân thể của mình thì mới có thể đạt tới mục tiêu hài hòa giữa con người và tự nhiên. Chính vì vậy, việc kế thừa quan niệm trời người hài hòa trong truyền thống có tác dụng tích cực đối với quá trình xây dựng xã hội hài hòa, đặc biệt là trong mô hình phát triển kinh tế cũng như cách thức xử lý vấn đề bảo vệ môi trường sinh thái.

Quan niệm hài hòa giữa con người và tự nhiên là một đặc trưng chủ yếu trong lịch sử triết học Trung Quốc. Chú trọng vào mối quan hệ giữa con người và tự nhiên là một trong những đặc điểm nổi bật của tư tưởng Trung Quốc truyền thống. Nhìn từ góc độ lịch sử triết học Trung Quốc, chúng ta có thể thấy một hiện tượng là hầu như nhà tư tưởng nào của Trung Quốc từ thời Tiên Tần cho đến cuối nhà Thanh đều có quan niệm trời - người của riêng mình. Các quan niệm trời - người của người Trung quốc có thể quy về ba hệ thống lớn: $i$. học thuyết thuận theo tự nhiên, quay về tự nhiên của Lão Tử; $i i$. học thuyết khắc chế tự nhiên của Tuân Tử; iii. học thuyết hài hòa giữa con người và tự nhiên của Kinh Dịch [2].

\section{Hài hòa giũua nguời với người}

Đạo "Nhân" của Nho giáo - trọng tâm của hoc thuyết xã họi hài hòa. "Nhân" là quan niệm chủ chốt của Nho giáo. Nhân không chỉ là một đức tính mà còn là nền tảng cho các mối quan hệ khác giữa con người với con người và con người với xã hội, con người với tự nhiên. Hàm nghĩa của khái niệm "nhân" này gồm hai điểm: thư nhất, $\dot{y}$ thức về cái chung và tâm vì mọi người. Con người có tấm lòng vì mọi người mới có thể thoát khỏi hạn chế của bản năng động vật để từ đó truy tìm sự hợp lý. Đây chính là nền tảng của mọi đức tính khác. Thú hai, nhân cũng là để chỉ ý chí mong muốn làm cho mọi vật được thành tưu. Nếu con người có thể thực sự làm cho tất cả mọi vật đều đạt được thành tựu của nó, thì con người có thể trở thành động lực cho mọi hoạt động xây dựng hay phát triển, tức là có thể sáng tạo ra văn hóa.

Tử Cống một học trò hỏi Khổng tử: $C o ́ m o ̂ ̣ t$ chũ nào để chúng ta phải thực hiện cả đời người không? - Khổng tử trả lời: chữ "Thứ". Ông giải thích thêm, những điều mình không muốn thì đừng đẩy cho người khác. Khổng tử nói với học trò khác là Tăng tử: "Sâm này, Đạo của thầy có một tư tưởng cơ bản xuyên suốt từ đầu chí cuối". Đó là hai chữ "Trung thứ". Trung nhấn mạnh nghĩa vụ và trách nhiệm mà mình phải gánh vác, thứ nhấn mạnh lòng khoan dung đối với người khác. Khổng tử coi "Đạo khoan dung" là chuẩn mực xử lý mối quan hệ của con người với con người. Sự khoan dung ở đây không phải là sự bao che, không để có thể lấn tới của người mắc lỗi, coi những làm bừa, làm sai như một thứ quyền lực đương nhiên, mà tiếp tục xâm phạm quyền của người khác, dung thứ những hành vi sai trái. Không lấy ân báo oán, cũng như không lấy oán báo oán, mà phải lấy chính trực báo oán. Khoan dung chân chính là tuân thủ nguyên tắc trong nhu có cương, ngoài tròn trong vuông; khoan dung với sai trái, nhưng phải với điều kiện người sai trái phải nhận rõ sai lầm và phải bảo đảm không tái diễn sai phạm $[3$, tr.114]. Khổng tử không đồng nghĩa khoan dung với xuề xòa, dễ dãi, tức là không lấy ân báo oán, cũng như oán báo oán, mà phải lấy chính trực báo oán [3, tr.118]. Đó là sự công bằng, lẽ công lý theo ngữ nghĩa của phương Tây.

Trong "Luận ngữ", Khổng Tử đã dùng hai câu để giải thích đạo nhân: "Mình muốn đứng vững thì làm cho người đứng vững, mình muốn thông suốt thì làm cho người thông suốt", "những gì mà mình không muốn thì đừng làm 
cho người khác", tức là đã xác định coi người khác như bản thân mình, thể hiện ý thức về cái chung và tâm vì mọi người, khẳng định hàm nghĩa công tâm chủ yếu của khái niệm nhân, cũng chính là nghĩa thứ nhất của khái niệm này, và nghĩa thứ hai dựa trên nghĩa thứ nhất mà có.

Trong "Luận ngư", khái niệm "nhân" (仁) được nhắc tới hơn 100 lần, thể hiện tầm quan trọng và vị trí của "nhân". Trong Nho giáo đức hạnh "nhân" và khái niệm "nhân" với nghĩa là người nhiều lúc được đồng nhất với nhau. "Thuyết văn giải tụ" giải thích chữ "nhân" là "hai người", mang hàm nghĩa thân thích, yêu thương, và quan hệ với nhau, tức là phải sống với nhau thành xã hội $[4$, tr.68]. Nhân nghĩa là sống với người khác, đối xử với người khác một cách lương thiện và tốt đẹp. Nhân không chỉ là sản phẩm của mối quan hệ qua lại giữa hai người hay nhiều người với nhau, mà còn là đặc tính căn bản của con người - họ không thể sống một cách độc lập riêng rẽ. Nội dung cơ bản của học thuyết nhân nghĩa Nho giáo là quan điểm yêu người. "Nhân" và "ái nhân" "nghĩa" là "hòa hợp, chính đáng". Yêu người nghĩa là "khắc chế bản thân, quay trở về với lễ", "tu duỡng bản thân để làm yên trăm họ". Tuy nhiên, yêu người cũng mang nghĩa phải lấy việc yêu thương người thân của mình làm điểm xuất phát: "đạo nhân, nghĩa là nguời, trước hết phải yêu thương nguời thân của mình". Nhân không những là yêu người, mà còn còn hài hòa, thích ứng và thương yêu người khác. Điều này là "Kẻ sĩ và người có lòng nhân, không vì sư sống của mình mà làm hại người khác mà chỉ tụ hy sinh bản thân để hoàn thành đạo nhân. Việc xây dựng xã hội hài hòa, tố chất tốt xấu nền tảng của con người tạo ra những tác động cơ bản đối với việc cấu thành các yếu tố nền tảng của xã hội hài hòa. Tư tưởng yêu người của Nho giáo một mặt đã nêu lên một trong những yếu tố giá trị nền tảng nhất, nó cũng biểu hiện một tinh thần thực tiễn có thể ảnh hưởng tích cực đến việc xây dựng xã hội hài hòa. Mạnh Tử đã từng nói: Quan niệm "thi hành ơn huệ rộng rãi cho nhân dân và cứu vớt nâng đỡ mọi ngườ" là chú trọng vào cái chung chứ không tập trung vào cá nhân, đồng thời thể hiện ý thức về cái chung và tâm vì mọi người. Nho giáo chú trọng đến cái chung không phải là để loại bỏ cá nhân, nhưng là đề cao cá nhân, làm cho cá nhân hoàn thiện hơn, nâng cao nhân cách và giá trị con người $[5$, tr.31-32]. Nho giáo nhấn mạnh đến việc quên cái riêng $t u$ cũng chính là để phát triển cái riêng. Khắc kỷ là để thi hành nhân nghĩa, đó là một tiền đề của sự hài hòa trong xã hội [2]. Con người là chủ thể của xã hội, nếu không có mối quan hệ giữa người với người thì vấn đề xã hội hài hòa sẽ chỉ là một vấn đề hư không. Điểm xuất phát của sự hài hòa trong quan hệ giữa người với người mà Nho giáo nói đến chính là sự đảm bảo của chế độ lễ nhạc. Học thuyết Khổng Tử có thể tóm tắt bằng cẩu nói trở thành thành ngữ: "Vua ra vua, tôi ra tôi, cha ra cha, con ra con" (Quân quân, thần thần, phụ phụ, tử tử) trong trật tự đẳng cấp này, mỗi thành viên trong xã hội đều làm đúng bồn phận và trách nhiệm của mình, tạo ra sự hài hòa trong xã hội" [2].

Sang đến thời kỳ cận hiện đại, do sự hấp thụ tinh thần dân chủ của phương Tây chế độ hài hòa được Tôn Trung Sơn nâng sự hài hòa lên thành chủ nghĩa Tâm dân: Dân trí, dân quyền và dân sinh. Nhưng chủ nghĩa của ông cũng chỉ dừng lại ở vùng lý thuyết mà chưa có điều kiện áp dụng vào thực tiễn của xã hội Trung quốc.

Đến thời kỳ hiện nay, sau một thời gian phát triển nóng, về kinh tế Trung quốc đã đạt được những thành công đáng kinh ngạc từ quốc gia nghèo đã trử thành một quốc gia có nền kinh tế đứng thứ hai trên thế giới, chỉ sau Mỹ quốc. Nhưng bên cạnh đó xã hội Trung quốc đang tồn tại những vấn nạn lớn, đó là tình trạng quá chênh lệch giữa giàu nghèo và tình trạng ô nhiễm. Để khắc phục những vấn nạn trên, nghị quyết về việc xây dựng xã hội hài hòa XHCN được thông qua tại Hội nghị Trung ương 6 (Khóa XVI) năm 2004 của ĐCS Trung Quốc. Mục tiêu của việc xây dựng xã hội hài hòa là nhằm giải quyết những vấn đề xã hội quan trọng khi Trung Quốc chuyển trọng tâm từ phát triển kinh tế sang thực hiện công bằng xã hội và phát triển bền vũng, giải quyết những mâu thuẫn xã hội trong quá trình phát triển kinh tế nhằm tạo ra môi trường xã hội tốt đẹp. Xã hội hài hòa XHCN, theo 
cách xác định của ĐCS Trung Quốc, là một xã hội "dân chủ pháp trị; công bằng chính nghĩa, thành thực giữ chữ tín và thương yêu nhau; tràn đầy sức sống, yên ổn có trật tự, con người chung sống hài hòa với tự nhiên" [6].

Từ thực tiễn xây dựng $\mathrm{CNXH}$ của Việt Nam và Trung Quốc, đặc biệt là thực tiễn của những năm cải cách, mở cửa và đổi mới của hai nước, vấn đề dân sinh đối với hai nước vẫn là vấn đề mang ý nghĩa thời sự cấp bách. Tuy mỗi nước có hoàn cảnh, điều kiện lịch sử cụ thể khác nhau, song đều lựa chọn con đường XHCN và đang tiến hành cải cách, đổi mới để xây dựng thành công $\mathrm{CNXH}$. Sự nghiệp cải cách của Trung Quốc và đổi mới của Việt Nam có ý nghĩa lịch sử to lớn, đã và đang tiếp thu được những thành tựu hết sức quan trọng. Trung Quốc tiến hành cải cách từ năm 1978 , còn Việt Nam tiến hành đổi mới từ năm 1986. Mục tiều của cải cách và đổi mới không gì khác hơn là nhằm nâng cao đời sống vật chất và tinh thần của nhân dân, xây dựng cuộc sống ngày càng hạnh phúc cho con người. Đó cũng chính là mục tiêu cơ bản trong chủ trương xây dựng xã hội hài hòa của Trung Quốc và chiến lược phát triển nhanh, bền vững của Việt Nam [6].

Việc xây dựng một xã hội hài hòa của Trung quốc nói riêng cũng như ở các nước phương Đông nói chung đã có ngay từ thời cổ đại manh nha qua các dòng tư tưởng nói trên, với mục đích bảo vệ cho sự tồn tại của chế độ mà chưa hướng đến mục đích bảo vệ quyền con người, trừ học thuyết Tam Dân của Tôn Trung Sơn. Tất cả những biểu hiện của xã hội hài hòa đều không được chế định thành luật, vì ở đó vẫn ngự trị một chế độ nhân trị, mà không phải là chế độ pháp quyền.

\section{Xây dựng xã hội hài hòa theo quan điểm của các nhà tư tưởng phương Tây và mục tiêu bảo vệ quyền con người}

Hài hòa được chế định hóa thành các quy định của pháp luật

Xã hội vốn mang nghĩa hài hòa. Đó là một trong những nguyên nhân tạo nên sự tồn tại của xã hội loài người. Nếu như những biểu hiện của một xã hội hài hòa ở phương Đông không được quy định cụ thể, thì ở phương Tây được quy định bằng các quyền của con người và các văn bản quy định về cơ cấu tổ chức hoạt động của các cơ quan nhà nước. Với Tây phương là société, society từ tiếng La tinh socius, có nghĩa companion, bạn cùng sống, bạn đồng hành. Khác với phương Đông, ở phương Tây ngay từ thời cổ đại với nền văn minh $\mathrm{Hy}$ La việc xây dựng xã hội đã gắn liền với pháp luật. Câu nói trở thành bất tử của Plato khi thấy rõ tầm quan trọng của pháp luật trong đời sống xã hội và đặc biệt là của việc tôn trọng thực hiện pháp luật: "Tôi nhìn thấy sự sụp đổ mau chóng của nhà nước ở nơi nào mà luật không có hiệu lục và nằm duoói quyền lực của một ai đó. Còn ở đâu mà luật đứng trên nhà cầm quyền, còn ho chỉ là nô lẹ của luật thì ở đó tôi nhìn thấy sư cưu thoát của nhà nước và tất cả các lợi ích mà chỉ có thuợng đế mới ban phát cho các nhà nước." [7, tr.188].

Aristotle một học trò của Plato đã tiếp thu và phát triển thành học thuyết chính trị của mình. Ông tin rằng chính thể tốt nhất phải được cai trị bởi những tầng lớp trung nông, vì họ hài hòa được lợi ích của các giai tầng xã hội còn lại. Trái lại với nhà nước lý tưởng Plato, nước "cộng hòa" của Aristotle không hướng đến chiến tranh mà hướng đến hòa bình và sự thư nhàn. Theo Aristote, pháp luật thể hiện rõ bản chất của nhà nước vì nhờ có pháp luật mà các quyền của công dân được thể hiện và được củng cố. Pháp luật có nhiệm vụ trợ giúp các cá nhân thỏa mãn trong các quan hệ nhằm thực hiện quyền của mình. Song quyền của con người không thống nhất giữa mọi người mà phải có sự khác biệt giữa người giàu và người nghèo. Tư tưởng về luật và về quyền của người dân của các ông đã được những người học trò sau này của họ phát triển thành quyền con người của phương Tây theo một lịch sử đến hàng nghìn năm: Quyền con người được mở rộng dần dần theo sự phát triển và sự đấu tranh của loài người từ nhà Vua cho đến những người có dòng dõi quý tộc, rồi chuyển qua người da trắng đàn ông có tài sản, rồi cho đến ngày nay 
của tất cả cho mọi người không phân biệt theo bất cứ một dấu hiệu nào kể từ tài sản đến giới tính, tôn giáo, học vị và cho tới màu da...

\section{Hài hòa phục vu con ngưòi}

Frédéric Bastiat (1801 -1850) là một triết gia người Pháp có nhiều đóng góp cho việc hình thành thuyết hài hòa của phương Tây. Bastiat nghĩ rằng, để cùng "sống chung" để "xã hội hoá", con người phải đi đến những giải pháp "hài hòa", "thương lượng". Quan niệm triết lý của Bastiat là một sự "hỗ tương", và cũng là "một liên đới của những đối nghịch". Chúng ta chỉ được thỏa mãn trong đời sống của mỗi chúng ta khi chúng ta tìm đáp số được cho sự sung túc chung của xã hội, nghĩa là sự thỏa mãn của những người khác. Chúng ta chỉ hưởng được phồn vinh trong một xã hội hoàn toàn đầy phồn vinh. Bastiat cũng nghĩ đến những khác biệt kỹ thuật cá nhân, nhưng tất cả phải phục vụ cho "con người". Sự đa dạng của nhu cầu cá thể sẽ là đáp số của sự đa dạng của kỹ thuật cá nhân. Bastiat đặt vai trò "con người” lên hàng đầu, quan trọng hóa vai trò "tiêu thụ" của con người bằng quyền và trách nhiệm của con người.

\section{Hài hòa không can thiẹp vào tự nhiên}

Thái độ của $\mathrm{F}$. Bastiat đối với tất cả những người khác được minh họa rõ bằng câu chuyện của một người khách du lịch: Một lần ông ta tới bộ lạc của những người bán khai, nơi có một đứa trẻ vừa chào đời. Một đám đông thầy bói, thầy cúng, thầy lang - trang bị vòng, móc và dây - đứng quanh nó. Một người nói: "Đứa trẻ này sẽ không bao giờ biết mùi thơm của ống điếu hòa bình trừ phi tôi căng lỗ mũi của nó ra". Một người khác nói: "Nó sẽ không bao giờ có thể nghe được, trừ phi tôi kéo dái tai của nó đến vai". Người thứ ba nói: "Nó sẽ không bao giờ nhìn thấy ánh nắng mặt trời, trừ phi tôi nghiêng mắt nó". Một người khác nói: "Nó sẽ không bao giờ đứng thẳng, trừ phi tôi uốn cong chân nó". Người thứ năm nói: "Nó sẽ không bao giờ học cách suy nghĩ, trừ phi tôi xoa đầu nó". "Dừng lại", ông khách kêu lên. "Những việc Chúa làm, đều đã được làm tốt rồi. Đừng nói rằng các vị biết nhiều hơn Ngài. Chúa đã ban cho sinh vật yếu đuối này các bộ phận; cứ để chúng phát triển và lớn mạnh nhờ luyện tập, sử dụng, trải nghiệm và tự do" [8, tr.158].

Sụ xung đột xã họi được giải quyết bằng đối thoại và thuơng thuyết

Trong xã hội mâu thuẫn sẽ thường xuyên xảy ra, giải quyết các mâu thuẫn trong xã hội Âu Mỹ là tổ chức một cuộc đối thoại thường trực giữa các bên thường là thông qua các hiệp hội. Công nhân hợp thành Nghiệp đoàn. Chủ nhân hợp thành các Hiệp hội chủ nhân. Và các cuộc thương thuyết, các cuộc gặp gỡ nhằm đem lại những giải pháp tổ chức cuộc "sống chung". Vai trò Nhà Nước chỉ làm trọng tài, tạo một cái sườn pháp lý, một cái khung đối thoại, và nếu cần, dùng "uy tín" để "phán những giải pháp", và những kết luận.

Con người của những xã hội văn minh đã nghĩ đến bản "Khế ước", đã biết thế nào là "dàn xếp", "hòa giải", và thế nào là "thị trường". Đó là biểu hiện của sự hài hòa trong xã hội. "Khế ước" là tinh thần làm luật, là tinh hoa của sự hài hòa, là cái "dàn xếp", cái mặc cả thỏa thuận, cái chữ "tín" giữa hai người. Đó là sự thể hiện của hài hòa xã hội khi giữa hai đối tượng, trọng nhau, và tin nhau cùng thỏa thuận với nhau.

Bằng con đường mọi người cùng ký kết với nhau một khế ước xã hội để thành lập ra nhà nước. J. Locke, nhà triết học lỗi lạc người Anh lập luận về việc ký kết khế ước xã hội như một phương thức thành lập ra nhà nước, bước vào xã hội chính trị của con người: "Con người, như đã nói, theo luật tự nhiên, tất cả đều tự do, bình đẳng và độc lập, không một ai có thể bị đưa ra khỏi tình trạng này và phải khuất phục trước quyền lực chính trị của người khác mà không có sự chấp thuận của chính người bị đặt ra. Cách duy nhất mà một người tước bỏ của chính mình quyền tự do tự nhiên và gắn với những ràng buộc của xã hội dân sự, là bằng sự đồng thuận với những người khác để cùng liên kết và hợp nhất trong một cộng đồng, vì cuộc sống tiện lợi, an toàn, và thanh bình giữa họ với nhau, trong sự thụ hưởng một cách bảo đảm đối với sở hữu của họ, và một sự an ninh lớn hơn trước đây, trong trạng thái tự nhiên, để chống lại bất cứ thứ gì không thuộc về điều đó. Bất kỳ 
thành viên nào của loài người cũng có thể thực hiện điều này, vì nó không gây phương hại đến tự do của những người còn lại; có thể nói, khi hành động như vậy, họ được để lại trong sự tự do của trạng thái tự nhiên. Khi có một lượng bất kỳ nào đó của loài người đã chấp thuận việc xây dựng một cộng đồng hay chính quyền, họ vì thế và tức khắc hợp thành tổ chức và làm nên một cơ thể chính trị, nơi mà đa số có quyền hành động và quyết định so với những người còn lại." [9, tr.137-138].

Sự hài hòa của xã hội Mỹ được Tocqueville phân tích trong tác phẩm Dân trị nước $M \tilde{y}$ (1835). Cống hiến lớn nhất của Tocqueville là người đầu tiên trong lịch sử tư tưởng chính trị thế giới đã nhìn ra mặt trái của nền dân chủ. Ông xem quyền lực tuyệt đối của đa số (thoát thai từ chủ quyền của nhân dân) là vấn nạn số một của nền dân trị Mỹ. Nguy cơ của một sự "chuyên chế của đa số" đối với lợi ích của thiểu số là nguy cơ thường trực. Trong vấn đề này, ông đã gây ảnh hưởng mạnh mẽ đến quan niệm tương tự của J. S. Mill khi ông viết Chính thể dại diện [10]. Theo Tocqueville, chính quyền dân chủ không yếu như người ta thường nghĩ mà là "quá mạnh" và, khác với Rousseau, ông xem quyền lực tuyệt đối của "ý chí chung" là "cái gì nguy hiểm và xấu từ bản chất". Vì thế, người công dân có quyền bất tuân lệnh một đạo luật bất công nhân danh "chủ quyền của con người" trên cả "chủ quyền của nhân dân", dù không hề phản đối đa số có "quyền ra lệnh". Trong khi đồng ý đa số dân chủ là nguồn gốc của mọi quyền lực, đồng thời phủ nhận rằng nó "có quyền nhân danh chính quyền để muốn làm gì thì làm". Ông viết:

"Có một châm ngôn mà tôi là vô đạo đức và đáng ghét, nói rằng trong việc cầm quyền thì phe đa số có quyền làm mọi điều, mặc dù tôi vẫn cho rằng phe đa số là nguồn gốc của mọi quyền lực. Liệu tôi có mâu thuẫn với chính mình không?...

Có những người không biết sợ khi nói rằng một quốc gia, đối với những mục tiêu chỉ liên quan đến đến riêng nó thôi, thì không sao có thể hoàn toàn thoát ra khỏi những giới hạn công lý và lý tính, và vì vậy ta chẳng nên e ngại gì việc trao toàn quyền cho phe đa số đại diện cho quốc gia đó. Nhưng nói lối đó là nói giọng của kẻ nô lệ.

Phe đa số gộp chung lại là cái gì nếu không phải là một cá thể có những ý kiến và rất nhiều khi có những lợi ích trái ngược với cá thể khác mà ta gọi là bằng phe thiểu số? Vậy mà, nếu ta thừa nhận một con người có đầy đủ mọi quyền lực có thể lạm dụng quyền lực đó để chống lại kẻ đối nghịch với mình, thì tại sao ta lại không thừa nhận cũng có những chuyện đó xảy ra đối với phe đa số? Con người khi quần tụ lại liệu có thay đổi tính nết không? Liệu khi họ mạnh hơn trước các trở lực thì họ có trở nên kiên nhẫn hơn không? Phần tôi, tôi chẳng tin như vậy, và các quyền được làm tất cả mà tôi từ chối không trao cho một người duy nhất trong đồng loại, tôi sẽ chẳng khi nào trao nó cho nhiều người." [ $[11$, tr.365-366].

Hài hòa bằng các quy định tổ chức quyền lực nhà nước

Sự hài hòa của phương Tây được quy định thành các quy định của pháp luật thông qua việc không những ghi nhận quyền con người trong từng lĩnh vực cụ thể, mà còn cả cơ chế bảo vệ việc thực thi trên thực tế các quyền này. Trước hết đó là cơ chế phân quyền giữa 3 quyền lập pháp, hành pháp và tư pháp. Phân quyền để bảo vệ nhân quyền. Đó là việc bảo vệ quyền của người thiểu số trước quyền của phe đa số. Sự hiện diện độc lập của quyền tư pháp cho phép nhà nước bảo vệ quyền của từng người dân trước các quyết định của chính quyền- nơi đại diện quyền lực của phe đa số. Sự hài hòa được biểu hiện rõ trong cơ cấu và hoạt động của nghị viện với cơ cấu 2 viện. Một viện đại diện cho giới bình dân, một viện đại diện giới thượng lưu, quý tộc như ở Anh, một viện cho quyền lợi của các tiểu bang không phân biệt đông dân hay dân thưa thớt, một viện đại diện cho mức độ dân số của các tiểu bang như ở Mỹ quốc...

Sự luật hóa thành những quy phạm cụ thể về quyền và trách nhiệm sẽ giúp cho phương Tây tránh khỏi những sai lầm, những mặt trái của hài hòa, dễ bị các chủ thể khác lợi dụng làm 
lợi cho mình. Đó là việc thể hiện tinh thần pháp quyền trong xã hội của họ.

\section{Kết luận}

Hài hòa xã hội như là một trong những biện pháp quan trọng được tồn tại trong nhận thức cũng trong thực tại của phát triển duy trì của mọi xã hội không những chỉ có ở phương Đông mà còn ở cả phương Tây. Nhưng giữa chúng, xã hội hài hòa có những biểu hiện và có những cách tiếp cận khác nhau. Sự khác nhau giữa tư tưởng xã hội hài hòa phương Tây và phương Đông nằm ở chỗ, nếu như phương Đông chỉ đề cập đến việc xây dựng một xã hội hài hòa với mục đích nhằm bảo vệ chế độ nói chung thể hiện qua các đức tính của người quân tử, thì ở phương Tây việc xây dựng một xã hội hài hòa được biểu cụ thể hơn là các quyền của con người, và phân quyền trong hệ thống pháp luật. Nhân quyền và phân quyền là 2 thuật ngữ được ghi nhận một cách phổ biến hiện nay trong các văn bản pháp luật của nhà nước phát triển, mà trước hết là Hiến pháp. Sự tiến hóa này có lẽ là một trong những nguyên nhân gây ra sự thăng hoa tiến bộ của nền văn minh phương Tây so với phương Đông, một xã hội pháp quyền, mà trong giai đoạn phát triển hiện nay của các nhà nước phương Đông, nhất là của các nước đang chuyển đổi từ một nền kinh tế tập trung sang một nền kinh tế thị trường định hướng xã hội chủ nghĩa, trong đó có cả Trung quốc và cả của Việt Nam đang bắt đầu của sự xây dựng.

\section{Tài liệu tham khảo}

[1] Phùng Hữu Lan: Lịch sử triết học Trung quốc Nxb. Khoa học Xã hội 2013.

[2] Nguyễn Tài Đông - Kỷ yếu hội thảo về vấn đề sở hữu và phát triển bền vững ở Việt Nam và Trung Quốc trong những năm đầu thế kỷ XXI /Viện Khoa học xã hội Việt Nam tháng 3 năm 2009.

[3] Xem: Nhẫn, Tần Tại Đông và Trần Hoa Châu chủ biên, Nxb. Chính trị quốc gia 2016.

[4] Xem: Tinh hoa văn hóa nhân loại, Nguyễn Văn Chử biên soạn. Nxb. Thông tin Văn hóa 2013.

[5] Cừu Bái Nhiên: Nhân học tản mặc. Nxb. Tổng hợp thành phố Hồ Chí Minh, 2011.

[6] Nguồn: Phạm Văn Đức, Đặng Hữu Toàn \& Nguyễn Đình Hòa (đcb) - Vấn đề dân sinh và xã hội hài hòa - NXB KHXH 2010.

[7] Platon, Tập 1, Matxcowva (bản tiếng Nga).

[8] F. Bastiat. Luật pháp, Nxb. Tri thức, 2015.

[9] John Locke, Khảo luận thứ hai về chính quyền dân sự. Nxb. Tri thức 2005.

[10] Bùi Văn Nam Sơn, Đọc lại về Tự do của John Stuart Mill", trong chuyên luận Trong ngần bóng gương, Tập kỷ yếu mừng GS.TS. Đặng Đình Áng 80 tuổi", Nxb.Tri thức, 12-2006.

[11] Xem, A. De Tocqueville, Nền Dân trị Mỹ. Nxb Trí thức 2006.

\title{
Building a Harmonious Society - the Purpose of Protecting the State or Protecting Human Rights
}

\author{
Nguyen Dang Dzung, Nguyen Dang Duy
}

VNU School of Law, 144 Xuan Thuy, Cau Giay, Hanoi, Vietnam

\begin{abstract}
The East refers to the construction of a harmonious society with the aim to protect the political regime in general, reflecting the virtues of a gentleman. While in the West, building a harmonious society shows specific expression of human rights and the state organization.
\end{abstract}

Keywords: Harmonious society, virtues of a gentleman, human rights, seperation power. 